Article

\title{
Physicochemical Properties and Oxidative Storage Stability of Milled Roselle (Hibiscus sabdariffa L.) Seeds
}

\author{
Nurul Hanisah Juhari ${ }^{1,2, *(1)}$ and Mikael Agerlin Petersen 1 (1) \\ 1 Department of Food Science, Faculty of Science, University of Copenhagen, Rolighedsvej 26, \\ Frederiksberg C, DK-1958, 1165 København, Denmark; map@food.ku.dk \\ 2 Department of Food Service and Management, Faculty of Food Science and Technology, \\ University Putra Malaysia, Serdang 43400, Selangor, Malaysia \\ * Correspondence: nurulhanisah.juhari@gmail.com; Tel.: +60-3-894-68-495; Fax: +60-3-894-85-970
}

Received: 3 January 2018; Accepted: 11 February 2018; Published: 11 February 2018

\begin{abstract}
Milled Roselle (Hibiscus sabdariffa L.) seeds of the UMKL cultivar were analyzed for proximate composition, water and oil absorption capacity, and the influence of storage conditions on storage stability. The storage stability was determined under four types of conditions: light/oxygen (air) (LO), light/nitrogen (LN), darkness/oxygen (air) (DO), and darkness/nitrogen (DN) while monitoring for seven consecutive months. During the storage period, the formation of volatiles was determined using dynamic headspace sampling and Gas Chromatography-Mass Spectrometry (GC-MS) analysis. In total, 85 volatiles were identified, mainly aldehydes, alcohols, ketones, furans, and acids indicating lipid oxidation. It is recommended that milled Roselle seeds should be flushed with nitrogen and stored in darkness. Under these conditions, the seeds can be stored for at least three months without changes in volatile profile. This is important to ensure the good quality of milled Roselle seeds for further commercialization.
\end{abstract}

Keywords: Roselle seeds; storage stability; gas chromatography-mass spectrometry; volatile compounds; principal component analysis; physicochemical properties

\section{Introduction}

Roselle (Hibiscus sabdariffa L.) is an annual erect, bushy, herbaceous shrub that can be found in almost all warm countries such as India, Saudi Arabia, Malaysia, Indonesia, Thailand, Philippines, Vietnam, Sudan, Egypt, and Mexico. Roselle is a very useful plant [1-3]. The most exploited part of the Roselle plant is its calyces but an underutilized by-product, the seeds, could also be valuable. In Malaysia, calyces are normally processed to produce juices and various food products; the seeds are removed and disposed of as a by-product. The Roselle seeds are, however, also edible [4]. Previous studies have shown that Roselle seeds contain high levels of protein (13-35.4\%), dietary fiber (18.3-42.6\%), lipid (17.4-29.6\%), and minerals (23.7-128 mg Ca, 596-672 mg P, 2.08-4.0 mg Zn, 0.21-3.1 mg Cu, 26.34-396 mg Mg, 0.08-0.18 mg Cr, and 0.36-0.51 mg riboflavin) [2,5-8]. In Nigeria, a decoction of the seeds is used to enhance lactation in cases of poor milk production and maternal mortality [9] and Nyam et al. [8] found that the seeds could be used as flour replacement for production of cookies enriched in protein and dietary fiber. In some countries, the seeds are roasted and consumed as a substitute for coffee [10].

Research done by Eltayeib and Elaziz [11] showed that Roselle seeds have a low content of free fatty acids, being indicative of low enzymatic hydrolysis, and are therefore well suited for preparation of food products. 
The lipid in Roselle seeds has a high content of polyunsaturated fatty acids (70\%) [12], which are highly vulnerable to oxidative deterioration. Before bringing production of Roselle seeds up to a commercial level, it is therefore crucial to know the stability of the product during storage. This can be done by identifying potential oxidation products that could contribute to the flavor i.e., as described by Holse et al. [13]. There are several factors that will influence the rate of lipid oxidation, namely fatty acid composition, moisture content, nature of the surface of the products, presence and activity of proand antioxidants, temperature, light, oxygen concentration and also relative humidity [13].

The overall aims of this study were to characterize the physicochemical properties of milled Roselle seeds and then to determine the influence of different storage conditions on the oxidative stability of milled Roselle seeds. From the storage experiment, suggested storage condition and shelf life will be given for the milled Roselle seeds.

\section{Results and Discussion}

\subsection{Physicochemical Properties}

The proximate composition, water absorption capacity (WAC) and oil absorption capacity (OAC) of milled Roselle seeds are presented in Table 1, together with values from literature. It is seen that dietary fiber is the major fraction in Roselle seeds, followed by protein, lipid, moisture, ash and carbohydrate. These values are grossly in accordance with other studies, although some differences are seen, probably due to different soil and climate conditions, agricultural practices [14], origin, and varieties. In general, Roselle seeds are a good source of dietary fiber compared to other common sources such as wheat and rice bran, oat and fiber from fruits [14]. Earlier studies have shown that Roselle seeds have high protein content compared with for example chickpea (Cicer arietinum L.), sunflower (Helianthus annuus L.), soybeans, groundnuts (Arachis hypogaea L.), and pigeon peas (Cajanus cajan L.) [15]. The lipid content of Roselle seeds is also considerable (16 to 30\%).

The WAC and OAC are important since they will affect the texture, consistency, and mouthfeel when seeds are used as an ingredient in a food product, for example bread $[6,7,16]$. The levels of WAC in milled Roselle seeds are high compared to standard wheat flour measured in our lab (118\%). A similar pattern is seen for OAC, where standard wheat flour has values of around $80 \%$.

\subsection{Monitoring of Oxygen and Nitrogen Levels in Packages}

The content of oxygen in the packages of milled Roselle seeds during storage is shown in Figure 1. For the packages that contained atmospheric air, a decrease in oxygen was seen during seven months of storage, most pronounced in samples stored in light. In the packages with nitrogen, the oxygen levels increased during storage, most in samples stored in the dark. The changes are a result of the balance between oxygen permeating through the packaging materials and oxygen removed due to oxidative processes within the package. The data in Figure 1 reveals that oxygen consumption is higher when packages are stored in light. In packages with air, the oxygen concentration decreases to a value close to zero, and it happens faster in packages stored in light. In packages with nitrogen, the higher oxygen increase in packages stored in the dark must be due to less oxygen consumption because the packages had identical geometry and therefore the same influx of oxygen. In fact, the oxygen level seems to stabilize in the samples stored in the light, indicating equal influx and consumption. In the samples stored in the dark, the oxidative processes are too slow to maintain a constant oxygen concentration. 
Table 1. Proximate composition, water and oil absorption capacity of different Roselle seed types.

\begin{tabular}{|c|c|c|c|c|c|c|c|c|c|c|}
\hline \multirow{3}{*}{ Type of Analysis } & \multirow{3}{*}{\begin{tabular}{|c|} 
Current Study \\
Malaysian \\
Sun Dried \\
\end{tabular}} & \multicolumn{9}{|c|}{ Previous Studies } \\
\hline & & \multirow[t]{2}{*}{ Egyptian $^{1}$} & \multicolumn{3}{|c|}{ Egyptian $^{2}$} & \multicolumn{2}{|c|}{ Indian $^{3}$} & \multicolumn{3}{|c|}{ Malaysian $^{4}$} \\
\hline & & & Light Red & Early Dark Red & Late Dark Red & Amw-2 & Bhimili-1 & Raw Freeze Dried & Sun Dried & Boiled Sun Dried \\
\hline Moisture content (\%) & $8.4 \pm 0.1$ & 7.6 & 9.3 & 11.7 & 11.5 & 8.6 & 6.7 & 6.8 & 9.9 & 9.8 \\
\hline Ash (\%) & $6.5 \pm 0.0$ & 7.0 & 6.9 & 5.8 & 6.5 & 5.4 & 5.4 & 7.4 & 7.5 & 6.6 \\
\hline Lipid (\%) & $16.2 \pm 0.5$ & 22.3 & 21.6 & 22.5 & 23.3 & 19.1 & 22.8 & 27.22 & 22.1 & 29.6 \\
\hline Protein $(\%)$ & $21.3 \pm 0.9$ & 15.4 & 31.0 & 30.1 & 30.9 & 18.8 & 22.3 & 35.4 & 33.5 & 30.6 \\
\hline Total dietary fiber (\%) & $47.3 \pm 1.4$ & ND & ND & ND & ND & 42.6 & 39.5 & 25.5 & 18.3 & 19.2 \\
\hline Crude fiber (\%) & ND & 15.3 & 4.1 & 3.4 & 1.2 & ND & ND & ND & ND & ND \\
\hline Carbohydrate $(\%)$ & $0.3 \pm 0.1$ & ND & 36.4 & 38.1 & 38.1 & ND & ND & 2.3 & 13.0 & 4.0 \\
\hline Water absorption capacity (\%) & $174.5 \pm 2.8$ & ND & 254 & 254 & 220 & ND & ND & ND & ND & ND \\
\hline Oil absorption capacity (\%) & $144.0 \pm 4.2$ & ND & 159 & 158 & 125 & ND & ND & ND & ND & ND \\
\hline
\end{tabular}

${ }^{1}$ Study done by Samy [17], ${ }^{2}$ El-Adawy and Khalil [6], ${ }^{3}$ Rao [2], and ${ }^{4}$ Hainida [18]. ND indicates not determined. 


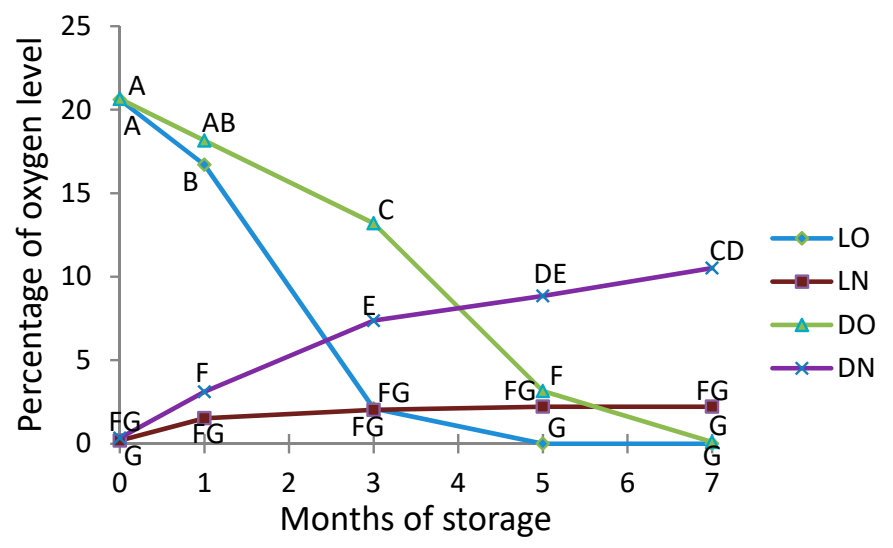

Figure 1. Effect of storage on oxygen levels in the headspace in milled Roselle seeds packed in the presence of oxygen (air) or nitrogen and stored under different light conditions (light or dark) for seven months. LO: samples stored in light in atmospheric air; LN: samples stored in light in nitrogen; DO: samples stored in darkness in atmospheric air; DN: samples stored in darkness in nitrogen. Observations marked with the same letter are not significantly different $(p>0.05)$.

\subsection{Volatile Compounds}

A total of 85 volatile compounds, including aldehydes (18), alcohols (18), ketones (11), furans (8), acids (10), esters (6), terpenes (3), pyrazines (2), sulfur-containing compounds (2), lactones (4), and miscellaneous (3) were identified in the samples. Table 2 shows retention index, significance values and odor description of volatile compounds identified. Significant differences among samples were observed for almost all volatile compounds. These results are in accordance with our previous work on aroma profile of Roselle seeds [19] (Table 2, compounds in bold). A Principal Component Analysis was carried out using the Gas Chromatography-Mass Spectrometry (GC-MS) peak areas (Figure 2). The first principal component (PC1) explained $48 \%$ of the variance while PC2 explained $14 \%$ of the variance.

In the PCA score plot (Figure 2A), a clear tendency can be seen that samples move to the right when storage time increases (higher values of PC1). It is also seen that samples stored in nitrogen move to the lower right (increasingly negative values of PC2) while samples stored in air have rather constant (small) positive values of PC2. The influence of light is less clear from these plots. From the score plot, it can be concluded that storage of up to three months only has a small effect on the volatile profile, except if samples are stored in air and light ('LO').

When scores and loadings are compared (Figure 2A,B) it is evident that the levels of almost all compounds increase during storage. This is especially the case for the compounds in the red ellipse, while compounds in the green ellipse increase most in samples with nitrogen atmosphere. The compounds that generally increase (red ellipse) are mainly linear aldehydes (butanal, pentanal, hexanal, (E)-2-heptenal, octanal, (E)-2-octenal, nonanal, $(E, E)$-2,4-nonadienal, and (E,E)-2,-decadienal), Strecker aldehydes (2-methylpropanal, 2-methylbutanal, 3-methylbutanal, and 2-methylpentanal), furans (2-propylfuran, 2-butylfuran, 2-pentylfuran, and 2-hexylfuran).

Up to three months, all linear aldehydes develop least in samples stored in the dark and most in the samples stored in air and light. After three months, the pattern becomes a little unclear, presumably because some aldehydes are broken further down, but, after seven months, all compounds except $(E, E)$-2,4-decadienal have the highest concentration in samples stored in air and light ('LO') (see Figure 3 showing hexanal and (E,E)-2,4-decadienal as examples). If samples are stored in nitrogen in the dark, no significant changes are seen during the first three months. Linear aldehydes are formed by oxidation of fatty acids. The oxidation can either be autoxidation, photooxidation or oxidation catalyzed by lipoxygenase, but since all create the same classes of secondary oxidation products, the present data cannot pinpoint which mechanism is the one dominating. It can be hypothesized that 
oxidation catalyzed by lipoxygenase is not very dominant, since this is the fastest. The fact that there is an effect of light indicates a combination of autoxidation and photooxidation to be the most prominent. Hexanal is often used as an indicator of oxidation, but many of the other aldehydes have also been reported to cause rancid off-flavors in a broad range of products [13,20,21].
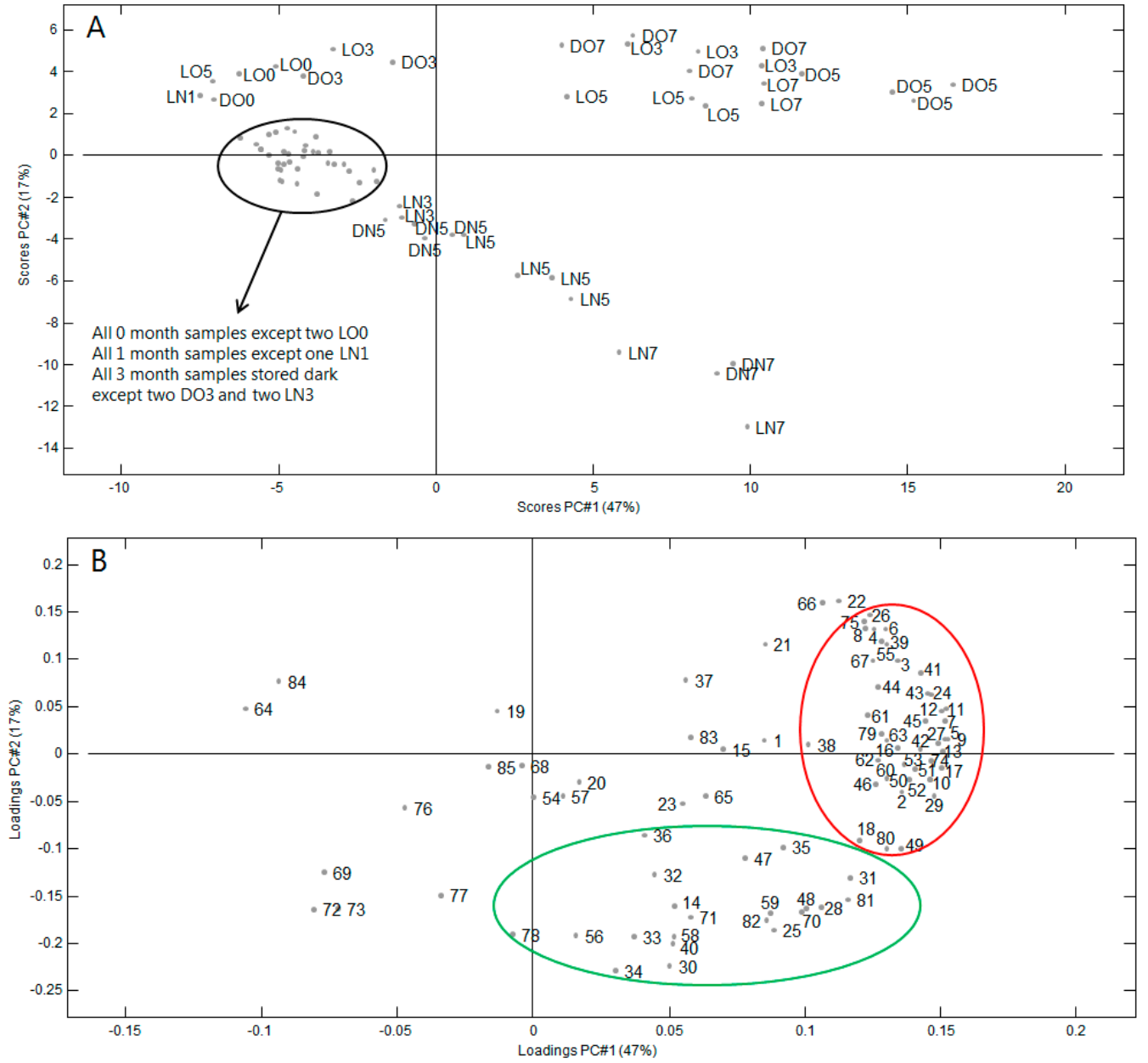

Figure 2. Principal component analysis (PCA) on autoscaled peak areas of volatiles in the headspace of milled Roselle seeds during storage. (A) score plot where LO: light/oxygen (atmospheric air); LN: light/nitrogen; DO: darkness/oxygen (atmospheric air); DN: darkness/nitrogen; numbers indicate storage time; (B) loadings plot where numbers refer to the compounds in Table 2.

Among the Strecker aldehydes, 2-methylbutanal, 3-methylbutanal, and 2-methylpentanal levels increase significantly in samples stored in air, while the increase is moderate or absent during storage in nitrogen. 2-Methylpropanal increases somewhat over time, but there is no clear relation to the storage conditions. As an example of a Strecker aldehyde, the development of 3-methylbutanal is shown in Figure 4. It is seen that, if stored in nitrogen, no significant increase will occur at any point of time. This is an even more pronounced effect of the nitrogen atmosphere than seen for the linear aldehydes. There is no clear effect of light. A positive effect of oxygen on the formation of Strecker aldehydes was also demonstrated by Wietstock et al. [22] during beer production and storage.

The furans are generally increasing over time, and it is a common tendency that the levels are dropping in the last part of the storage when samples are stored with air (see Figure 5 showing 2-pentylfuran as an example). Again, there is no change during the first three months if the samples are stored in nitrogen. The effect of light is not clear. 
Table 2. Volatile compounds identified by Gas Chromatography-Mass Spectrometry (GC-MS) in the packed milled Roselle (Hibiscus sabdariffa L.) seeds stored for seven months in the presence or absence of oxygen and under different light conditions (light or darkness). Volatiles in bold were detected in our previous work on aroma profile of Roselle seeds [19].

\begin{tabular}{|c|c|c|c|c|c|c|c|}
\hline \multicolumn{2}{|c|}{ Compounds } & \multicolumn{2}{|c|}{ Retention Index } & \multicolumn{3}{|c|}{ Significance $^{h}$} & \multirow{2}{*}{ Odor Description (from Literature) } \\
\hline & & Exp & Auth/Litt ${ }^{\text {a }}$ & Storage & Oxygen & Light & \\
\hline \multicolumn{8}{|c|}{ Aldehydes } \\
\hline 1 & 2-Methylpropanal & 811 & 770-834 & $* * *$ & * & ns & Pungent, burnt, malty, grain ${ }^{\mathrm{e}}$ \\
\hline 2 & Butanal & 873 & $830-911$ & $* * *$ & ns & $* * *$ & Green, plastic-like ${ }^{c}$, floral ${ }^{\mathrm{d}}$ \\
\hline 3 & 2-Methylbutanal & 911 & Auth & $* * *$ & $* * *$ & ns & Cocoa, almond, malty ${ }^{\mathrm{b}}$, fermented ${ }^{\mathrm{e}}$ \\
\hline 4 & 3-Methylbutanal & 915 & Auth & $* * *$ & $* * *$ & ns & Fruity, toasted, malty, green ${ }^{c}$ \\
\hline 5 & Pentanal & 979 & Auth & $* * *$ & $* * *$ & $*$ & Almond, malty, pungent ${ }^{c}$, oily, green ${ }^{e}$ \\
\hline 6 & 2-Methylpentanal & 989 & & $* * *$ & $* * *$ & ns & Unpleasant, rotten apples c \\
\hline 7 & Hexanal & 1093 & Auth & $* * *$ & $* * *$ & ns & Grassy, tallow, fatty $\mathrm{b}^{\mathrm{s}}$ \\
\hline 8 & 2-Methyl-(E)-2-butenal & 1092 & & $* * *$ & $* * *$ & ns & Green, pungent, nutty, ethereal ${ }^{d}$ \\
\hline 9 & Octanal & 1303 & Auth & $* * *$ & $* * *$ & $*$ & Citrus, waxy $\mathrm{d}$ \\
\hline 10 & (E)-2-Heptenal & 1335 & $1273-1366$ & $* * *$ & $* *$ & $* * *$ & Green, vegetable, fatty ${ }^{\mathrm{d}}$ \\
\hline 11 & 2-Ethyl-2-hexenal & 1345 & 1322 & $* * *$ & $* * *$ & ns & Fatty, citrus, green ${ }^{b}$, grassy, soapy ${ }^{e}$ \\
\hline 12 & Nonanal & 1399 & Auth & $* * *$ & $* * *$ & ns & Fatty e \\
\hline 13 & (E)-2-Octenal & 1437 & 1393-1467 & $* * *$ & $* *$ & ns & Green, nutty, fatty ${ }^{b}$, waxy, mushroom ${ }^{c}$ \\
\hline 14 & Benzaldehyde & 1532 & Auth & $* * *$ & ns & * & Almond, burnt, sugar ${ }^{b}$ \\
\hline 15 & Benzeneacetaldehyde & 1653 & $1592-1684$ & ** & $* * *$ & ns & Green, hyacinth ${ }^{d}$ \\
\hline 16 & 2-Butyl-2-octenal & 1679 & $1640-1688$ & $* * *$ & * & ns & Green, citrus, grassy, fruity $\mathrm{g}, *$ \\
\hline 17 & 2,4-Nonadienal & 1714 & $1660-1740$ & $* * *$ & $* *$ & ns & Watermelon, fatty, waxy, green ${ }^{b}$ \\
\hline 18 & 2,4-Decadienal & 1826 & $1763-1858$ & $* * *$ & ns & ns & Fatty, fried ${ }^{d}$ \\
\hline \multicolumn{8}{|c|}{ Alcohols } \\
\hline 19 & 2-Propanol & 935 & 884-975 & ns & ns & ns & Alcoholic, musty, woody ${ }^{d}$ \\
\hline 20 & 2-Butanol & 1036 & 989-1057 & ns & ns & $* * *$ & Fruity, sweet, apricot ${ }^{d}$ \\
\hline 21 & Propanol & 1049 & Auth & $* *$ & $* * *$ & ns & Alcoholic, fermented ${ }^{\mathrm{d}}$ \\
\hline 22 & 2-Methyl-1-propanol & 1105 & Auth & $* * *$ & $* * *$ & ns & Ethereal, winey, whiskey d \\
\hline 23 & 1-Methoxy-2-propanol & 1138 & $1108-1160$ & $*$ & ns & ns & Mild, ethereal, weak pleasant ${ }^{\mathrm{f}}$ \\
\hline 24 & Butanol 1 - 1 & 1162 & Auth & $* * *$ & $* * *$ & ns & Fusel, oily ${ }^{d}$ \\
\hline 25 & 1-Penten-3-ol & 1175 & $1112-1207$ & $* * *$ & $* * *$ & ns & Pungent, buttery, milky ${ }^{c}$ \\
\hline 26 & 3-Methyl-1-butanol & 1222 & Auth & $* * *$ & $* * *$ & ns & Fermented, fusel, alcoholic, whiskey ${ }^{d}$ \\
\hline 27 & Pentanol & 1271 & Auth & $* * *$ & $* *$ & ns & Alcohol, pungent, fruity, balsamic ${ }^{b}$ \\
\hline 28 & 2-Heptanol & 1339 & 1280-1344 & $* * *$ & $* *$ & $*$ & Citrus, herbal, floral, green ${ }^{\mathrm{d}}$ \\
\hline 29 & Hexanol & 1369 & Auth & $* * *$ & ns & * & Resin, flowery, green $\mathrm{b}$ \\
\hline
\end{tabular}


Table 2. Cont

\begin{tabular}{|c|c|c|c|c|c|c|c|}
\hline \multirow{2}{*}{\multicolumn{2}{|c|}{ Compounds }} & \multicolumn{2}{|c|}{ Retention Index } & \multicolumn{3}{|c|}{ Significance $^{h}$} & \multirow{2}{*}{ Odor Description (from Literature) } \\
\hline & & Exp & Auth/Litt ${ }^{a}$ & Storage & Oxygen & Light & \\
\hline \multicolumn{8}{|c|}{ Alcohols } \\
\hline 30 & 2-Octanol & 1431 & $1380-1430$ & $* * *$ & $* * *$ & * & Spicy, fresh, green, woody, earthy ${ }^{\mathrm{d}}$ \\
\hline 31 & 1-Octen-3-ol & 1460 & Auth & $* * *$ & $*$ & $* * *$ & Mushroom, earthy ${ }^{c}$ \\
\hline 32 & Octanol & 1570 & Auth & ns & ns & ns & Mushroom, moss, nutty, burnt ${ }^{b}$ \\
\hline 33 & 2,3-Butanediol & 1592 & $1492-1620$ & $* * *$ & $* * *$ & ns & Fruity, creamy, buttery \\
\hline 34 & 2-Decanol & 1628 & $1585-1622$ & $* *$ & $* *$ & ns & Fatty, waxy, floral, orange, sweet ${ }^{d}$ \\
\hline 35 & Benzyl alcohol & 1892 & Auth & $* * *$ & ns & * & Sweet, flowery ${ }^{b}$ \\
\hline 36 & Phenethyl alcohol & 1929 & Auth & ns & ns & ns & Honey, spice, rose, lilac ${ }^{b}$ \\
\hline \multicolumn{8}{|c|}{ Ketones } \\
\hline 37 & Acetone & 814 & 775-847 & $* * *$ & * & ns & Solvent, ethereal ${ }^{\mathrm{d}}$ \\
\hline 38 & 2-Butanone & 903 & Auth & $* * *$ & * & $* * *$ & Chemical-like, ether-like, cheesy $^{c}$ \\
\hline 39 & 3-Methyl-2-butanone & 925 & 918-989 & $* * *$ & $* * *$ & ns & Acetone-like ${ }^{\mathrm{f}}$ \\
\hline 40 & 1-Penten-3-one & 1018 & $973-1056$ & $* * *$ & $* * *$ & ns & Pungent, rotten, fruity, plastic-like ${ }^{c}$ \\
\hline 41 & 2-Octanone & 1298 & Auth & $* * *$ & $* * *$ & ns & Soap, gasoline-like ${ }^{b}$ \\
\hline 42 & 6-Methyl-5-hepten-2-one & 1349 & 1296-1368 & $* * *$ & $* * *$ & ns & Mushroom, woody, rubbery ${ }^{f}$, fruity ${ }^{e}$ \\
\hline 43 & 2-Nonanone & 1396 & Auth & $* * *$ & $* * *$ & ns & Hot milk, soap, green, blue cheese ${ }^{b}$ \\
\hline 44 & 3-Octen-2-one & 1415 & $1392-1411$ & $* * *$ & $* * *$ & ns & Nutty, blueberry, oily, fruity, green ${ }^{\mathrm{e}}$ \\
\hline 45 & 2-Decanone & 1502 & 1463-1519 & $* * *$ & $* * *$ & ns & Floral, orange, fatty, peach ${ }^{\mathrm{d}}$ \\
\hline 46 & 3-Nonen-2-one & 1522 & 1523 & $* * *$ & * & $* *$ & Fruity, berry, brandy, mushroom ${ }^{d}$ \\
\hline 47 & 3,5-Octadien-2-one & 1581 & $1521-1610$ & * & ns & ns & Fruity, green, grassy ${ }^{d}$ \\
\hline \multicolumn{8}{|c|}{ Furans } \\
\hline 48 & 2-Ethylfuran & 948 & 923-975 & $* * *$ & $* *$ & ns & Rubbery, pungent, acid, sweet ${ }^{\mathrm{c}}$ \\
\hline 49 & 2-Propylfuran & 1030 & $1011-1043$ & $* * *$ & ns & ns & Heated peanut, apricot, plum ${ }^{\mathrm{f}}$ \\
\hline 50 & 2-Butylfuran & 1143 & $1088-1140$ & $* * *$ & ns & ns & Mild, fruity, wine, sweet, spice ${ }^{c}$ \\
\hline 51 & 2-Pentylfuran & 1242 & 1193-1258 & $* * *$ & ns & $* *$ & Green bean, buttery ${ }^{b}$, green, pungent ${ }^{e}$ \\
\hline 52 & 2-Hexylfuran & 1343 & $1312-1345$ & $* * *$ & ns & ns & 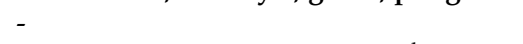 \\
\hline 53 & 2-Heptylfuran & 1440 & $1416-1454$ & $* * *$ & ns & ns & Green, fatty, oily, roasted nutty ${ }^{d}$ \\
\hline 54 & Furfural & 1472 & Auth & * & ns & ns & Bread, almond, sweet ${ }^{b}$, fruity, wood ${ }^{c}$ \\
\hline 55 & Dihydro-4,5-dimethyl-2(3H)-furanone & 1619 & $1590-1624$ & $* * *$ & $* * *$ & ns & Caramel, sweet, candy d \\
\hline \multicolumn{8}{|c|}{ Acids } \\
\hline 56 & Acetic acid & 1446 & $1401-1485$ & $* * *$ & $* * *$ & ns & Vinegar $^{b}$ \\
\hline 57 & Propanoic acid & 1545 & $1487-1570$ & ns & ns & ns & Pungent, rancid, soy $\mathrm{b}$ \\
\hline 58 & 2-Methylpropanoic acid & 1574 & $1520-1608$ & $* * *$ & $* * *$ & ns & Acidic, sour, cheesy, dairy, rancid ${ }^{\mathrm{d}}$ \\
\hline 59 & Butanoic acid & 1634 & $1556-1674$ & $* * *$ & $* * *$ & ns & Cheesy, sharp, acetic, buttery, fruity ${ }^{\mathrm{d}}$ \\
\hline
\end{tabular}


Table 2. Cont

\begin{tabular}{|c|c|c|c|c|c|c|c|}
\hline \multirow{2}{*}{\multicolumn{2}{|c|}{ Compounds }} & \multicolumn{2}{|c|}{ Retention Index } & \multicolumn{3}{|c|}{ Significance $^{\mathrm{h}}$} & \multirow{2}{*}{ Odor Description (from Literature) } \\
\hline & & Exp & Auth/Litt ${ }^{a}$ & Storage & Oxygen & Light & \\
\hline \multicolumn{8}{|c|}{ Acids } \\
\hline 60 & 2-Methylbutanoic acid & 1678 & $1638-1706$ & $* * *$ & ns & ns & Acidic, pungent, cheesy ${ }^{\mathrm{d}}$ \\
\hline 61 & 3-Methylbutanoic acid & 1676 & $1631-1707$ & $* * *$ & * & ns & Cheesy, sour, sweaty, tropical ${ }^{\mathrm{d}}$ \\
\hline 62 & Pentanoic acid & 1745 & $1686-1766$ & $* * *$ & ns & ns & Cheesy, acidic, sweaty, rancid d \\
\hline 63 & Hexanoic acid & 1854 & $1797-1880$ & $* * *$ & $*$ & ns & Sweaty, cheesy, rancid, goat-like ${ }^{c}$ \\
\hline 64 & Heptanoic acid & 1961 & 1913-2000 & $* * *$ & ns & ns & Cheesy, rancid, sour, sweaty ${ }^{d}$ \\
\hline 65 & Octanoic acid & 2071 & $2011-2100$ & $*$ & ns & ns & Fatty, rancid, vegetable, cheesy ${ }^{d}$ \\
\hline \multicolumn{8}{|c|}{ Esters } \\
\hline 66 & Ethyl acetate & 891 & $850-914$ & $* * *$ & $* * *$ & ns & Pineapple $^{b}$, fruity, orange ${ }^{c}$ \\
\hline 67 & Ethyl pentanoate & 1147 & Auth & $* * *$ & $* * *$ & ns & Fruity, apple, pineapple, green $\mathrm{d}$ \\
\hline 68 & Ethyl lactate & 1357 & $1342-1356$ & ns & ns & ns & Fruity, creamy ${ }^{d}$ \\
\hline 69 & Methyl acetate & 826 & $782-877$ & $* * *$ & $* * *$ & $* * *$ & Fruity, solvent-like, blackcurrant ${ }^{\mathrm{c}}$ \\
\hline 70 & Methyl octanoate & 1397 & Auth & $* * *$ & $*$ & $* *$ & Orange $^{b}$ \\
\hline 71 & Methyl nonanoate & 1500 & $1476-1536$ & $* * *$ & $* *$ & $* * *$ & Coconut ${ }^{\mathrm{b}}$ \\
\hline \multicolumn{8}{|c|}{ Terpenes } \\
\hline 72 & $\alpha$-Pinene & 1014 & Auth & $* * *$ & $* * *$ & $*$ & Herbal, pine, woody ${ }^{\mathrm{d}}$ \\
\hline 73 & Eucalyptol & 1207 & $1173-1246$ & $* * *$ & $* *$ & * & Herbal, eucalyptus, minty \\
\hline 74 & $\alpha$-Terpineol & 1711 & Auth & $* * *$ & $* * *$ & ns & Pine, lilac, citrus, woody, floral ${ }^{\mathrm{d}}$ \\
\hline \multicolumn{8}{|c|}{ Pyrazines } \\
\hline 75 & 2,6-Dimethylpyrazine & 1342 & $1300-1355$ & $* * *$ & $* * *$ & ns & Cocoa, roasted, nutty ${ }^{\mathrm{d}}$ \\
\hline 76 & Tetramethyl pyrazine & 1490 & $1438-1486$ & $* * *$ & ns & $*$ & Nutty, musty, chocolate, coffee ${ }^{\mathrm{e}}$ \\
\hline \multicolumn{8}{|c|}{ Sulfur-containing compounds } \\
\hline 77 & Dimethyl sulfide & 743 & 715-804 & ns & $* * *$ & ** & Sulfurous, onion, sweet corn ${ }^{\mathrm{d}}$ \\
\hline 78 & Dimethyl disulfide & 1068 & $1036-1127$ & * & $* * *$ & * & Sulfurous, cabbage, onion ${ }^{\mathrm{d}}$ \\
\hline \multicolumn{8}{|c|}{ Lactones } \\
\hline 79 & gamma-Butyrolactone & 1642 & $1593-1673$ & $* * *$ & ns & * & Creamy, oily, fatty ${ }^{d}$ \\
\hline 80 & gamma-Hexalactone & 1718 & $1655-1745$ & $* * *$ & ns & ns & Creamy, vanilla d \\
\hline 81 & gamma-Octalactone & 1938 & $1867-1945$ & $* * *$ & * & ns & Creamy, coconut ${ }^{\mathrm{d}}$ \\
\hline 82 & gamma-Nonalactone & 2052 & $1981-2062$ & $* * *$ & $* *$ & ns & Floral, waxy, metallic, plum ${ }^{d}$ \\
\hline
\end{tabular}


Table 2. Cont

\begin{tabular}{|c|c|c|c|c|c|c|c|}
\hline \multirow{2}{*}{\multicolumn{2}{|c|}{ Compounds }} & \multicolumn{2}{|c|}{ Retention Index } & \multicolumn{3}{|c|}{ Significance $^{\mathrm{h}}$} & \multirow{2}{*}{ Odor Description (from Literature) } \\
\hline & & $\operatorname{Exp}$ & Auth/Litt ${ }^{a}$ & Storage & Oxygen & Light & \\
\hline \multicolumn{8}{|c|}{ Miscellaneous } \\
\hline 83 & Phenol & 2015 & 1949-2037 & ns & ns & ns & Phenolic, medicinal ${ }^{\mathrm{c}}$ \\
\hline 84 & Ethyl ether & 618 & $570-619$ & $* * *$ & ns & ns & Ethereal $^{\mathrm{d}}$ \\
\hline 85 & Theaspirane & 1555 & $1472-1553$ & ns & ns & ns & Herbal, tea, green, woody, spicy ${ }^{\mathrm{d}}$ \\
\hline
\end{tabular}



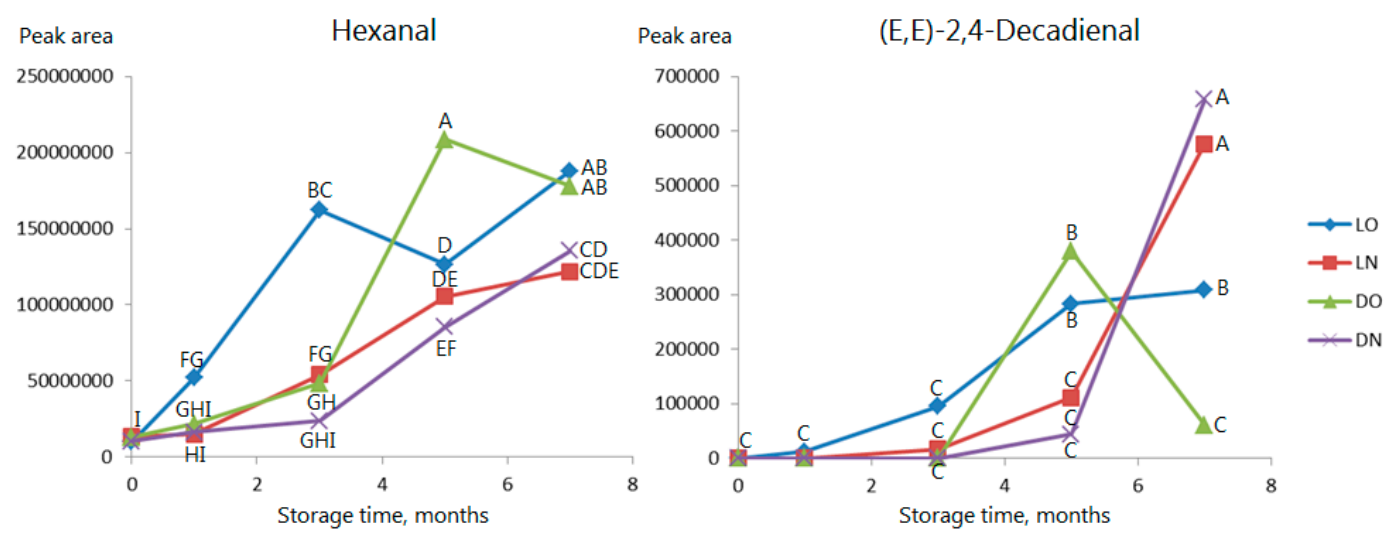

Figure 3. Effect of storage on levels of hexanal and $(E, E)$-2,4-decadienal in the headspace of milled Roselle seeds. LO: light/oxygen (atmospheric air); LN: light/nitrogen; DO: darkness/oxygen (atmospheric air); DN: darkness/nitrogen. Observations marked with the same letter are not significantly different $(p>0.05)$.

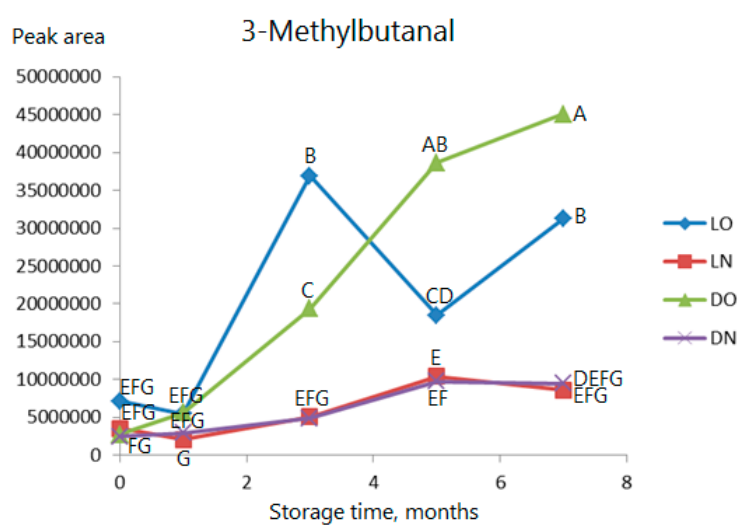

Figure 4. As Figure 3 but data for 3-methylbutanal. Observations marked with the same letter are not significantly different $(p>0.05)$.

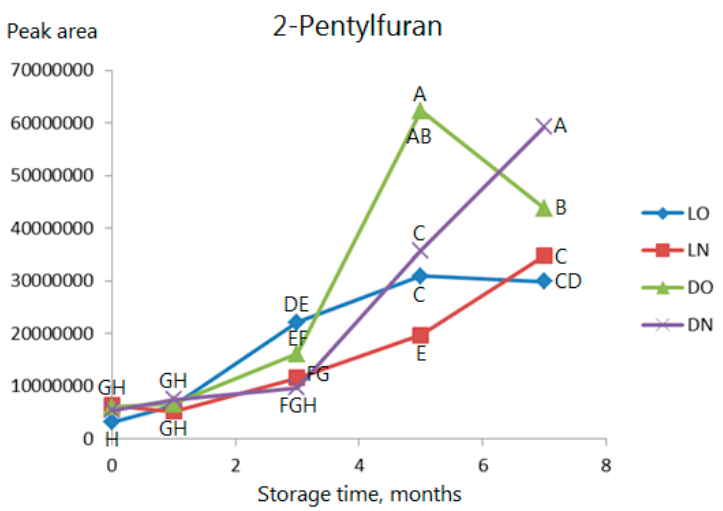

Figure 5. As Figure 3 but data for 2-pentylfuran. Observations marked with the same letter are not significantly different $(p>0.05)$.

The compounds that increase most in samples with nitrogen atmosphere (green ellipse in Figure 2B) are mainly alcohols (1-penten-3-ol, 2-heptanol, 2-octanol, 1-octen-3-ol, octanol, 2,3-butanediol, 2-decanol, benzyl alcohol, and phenylethyl alcohol) and acids (acetic acid, 2-methylpropanoic acid, and butanoic acid). 
1-Octen-3-ol is shown in Figure 6 as an example of an alcohol. It is seen that, although it reaches the same high level after dark and light storage in nitrogen, the increase starts earlier in samples stored in light. Samples stored in dark exhibit no increase during the first three months.

Acetic acid is shown in Figure 7 as an example of an acid. When oxygen is present, there is almost no production of acids, but, in nitrogen, significant production is observed when stored more than three months.

Most of the mentioned alcohols and acids can be related to lipid oxidation and/or microbial growth. It could be hypothesized that microbial counts do not influence levels until late in the storage period, and the reason that it dominates in the packages with nitrogen could be that oxygen levels actually are highest late in the storage period (Figure 1). Microbiology was, however, not included in the present study, but could the subject of future studies.

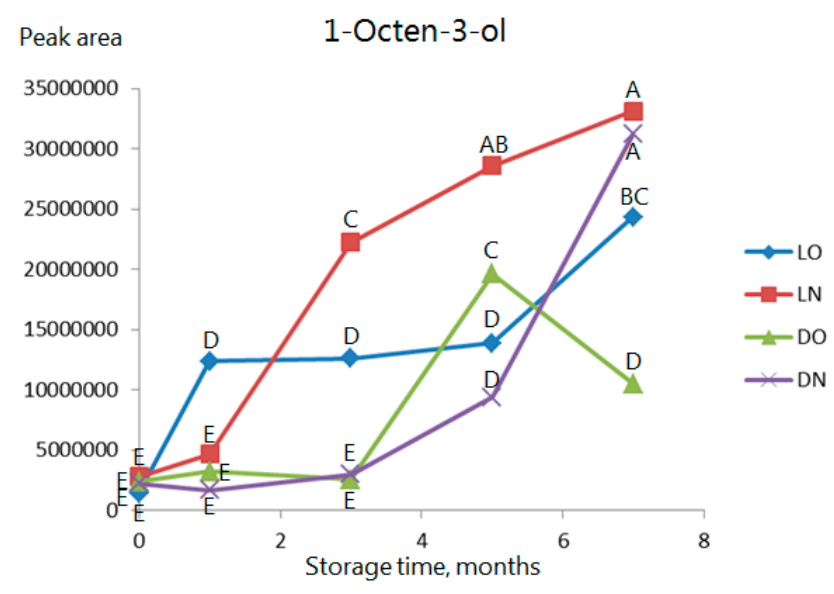

Figure 6. As Figure 3 but data for 1-octen-3-ol. Observations marked with the same letter are not significantly different $(p>0.05)$.

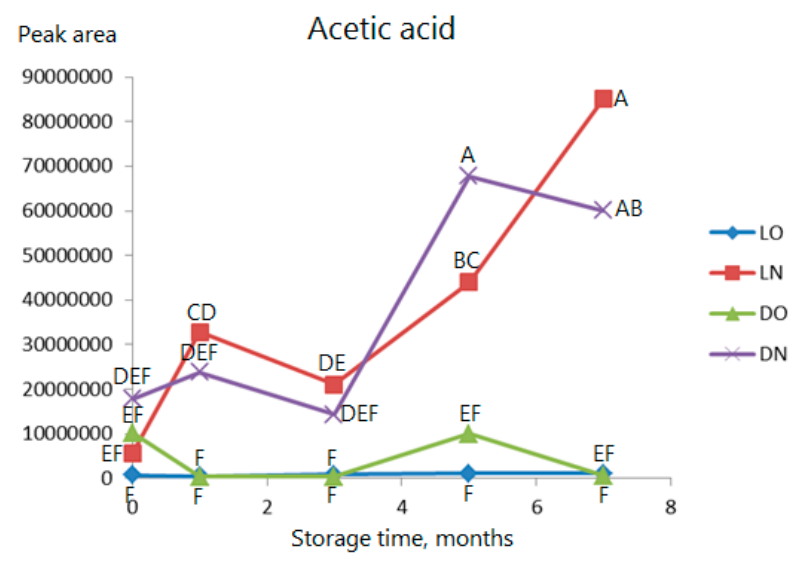

Figure 7. As Figure 3 but data for acetic acid. Observations marked with the same letter are not significantly different $(p>0.05)$.

Overall, the observations from the PCA are confirmed: There are practically no significant changes within the first three months of storage if samples are stored in nitrogen and in the dark. Furthermore, an effect of light was seen primarily on linear aldehydes and alcohols. 


\section{Materials and Methods}

\subsection{Chemical Standards}

Chemical standards of volatile compounds, alkane standard mixture, petroleum ether, sodium hydroxide, ethanol, concentrated sulfuric acid, boric acid, hydrochloric acid, and acetone were obtained from Sigma-Aldrich/Merck (Merck KGaA, Darmstadt, Germany). Enzyme and celite, acid-washed, pre-ashed (Megazyme G-EL100 or G-CEL500) were supplied by Megazyme International Ireland Limited (Wicklow, Ireland).

\subsection{Sample Materials}

Sun dried Roselle (Hibiscus sabdariffa L.) seeds of the UMKL cultivar (obtained from HERBagus Sdn. Bhd., Penang, Malaysia) were chosen for the study. Identification of plant species was based on taxonomic descriptions and photographic illustrations by botanist Dr Shamsul Khamis from Institute of Bioscience, University Putra Malaysia. Roselle seeds were received from HERBagus as one batch of $6 \mathrm{~kg}$ from which representative samples were drawn. The samples were manually sorted to remove dirt and other extraneous matter. The samples were stored at $-24^{\circ} \mathrm{C}$ in glass jars flushed with nitrogen. Prior to the physicochemical analysis and storage experiment, the seeds were taken out from the freezer and milled for $90 \mathrm{~s}$ using a laboratory blender Model 38BL41 (Waring, CT, USA). The particle size of the milled Roselle seeds was as follows: $2.2 \%$ of the milled seeds had a particle size less than $75 \mu \mathrm{m}$; $13.3 \%$ between $75 \mu \mathrm{m}$ and $160 \mu \mathrm{m} ; 13.6 \%$ between $160 \mu \mathrm{m}$ and $250 \mu \mathrm{m} ; 27.5 \%$ between $250 \mu \mathrm{m}$ and $500 \mu \mathrm{m} ; 39.5 \%$ between $500 \mu \mathrm{m}$ and $1000 \mu \mathrm{m}$, and only 3.9\% had a particle size bigger than $1000 \mu \mathrm{m}$.

\subsection{Chemical and Physical Analyses}

\subsubsection{Proximate Analysis}

Proximate analysis of the milled Roselle seeds was performed according to the standard Association of Official Analytical Chemist (AOAC) method [24]. Moisture content (hot-air oven method), ash (dry ashing method), lipid (Soxhlet extraction), protein (Micro-Kjeldahl method), total dietary fiber [25] and carbohydrates (by difference) were analyzed and calculated. All measurements were conducted in triplicate. The results were expressed as a percentage (wet weight).

\subsubsection{Water and Oil Absorption Capacities}

Bhat and Yahya's method [16] was employed for the determination of water and oil absorption capacity. One gram of the milled Roselle seeds was mixed with distilled water or oil $(10 \mathrm{~mL})$ in a centrifuge tube and allowed to stand at room temperature $\left(25^{\circ} \mathrm{C}\right)$ for $1 \mathrm{~h}$. After this time period, samples were centrifuged $(200 \times g \mathrm{rpm}$ for $30 \mathrm{~min})$. WAC or OAC were expressed as percentage of water or oil absorbed by $1 \mathrm{~g}$ of the milled seeds. All measurements were carried out in triplicates.

\subsection{Packaging and Storage Conditions}

The milled Roselle seeds were packed in transparent plastic laminate bags (PA/PE 20/70) with an oxygen transmission rate (OTR) of $32 \mathrm{~mL} / \mathrm{m}^{2} / 24 \mathrm{~h} / \mathrm{atm}\left(23{ }^{\circ} \mathrm{C}, 75 \% \mathrm{RH}\right)$ and a water vapor transmission rate (WVTR) of $1.0 \mathrm{~g} / \mathrm{m}^{2} / 24 \mathrm{~h}\left(23^{\circ} \mathrm{C}, 85 \% \mathrm{RH}\right)$. Each bag was filled with $85 \mathrm{~g}$ of milled Roselle seeds and then either sealed under atmospheric conditions (21\% oxygen) or flushed with nitrogen ( $<1 \%$ oxygen). The bags were packed using a Komet Digi-Gas Packaging Machine (Mirovac X200, Plochingen, Germany). Two replicate bags were prepared for each storage condition and for each month of analysis. The samples were represented as follows:

LO (Light/Oxygen): samples stored in light in atmospheric air,

LN (Light/Nitrogen): samples stored in light in nitrogen,

DO (Darkness/Oxygen): samples stored in darkness in atmospheric air, 
DN (Darkness/Nitrogen): samples stored in darkness in nitrogen.

The samples stored in light were placed in a room without direct sunlight and with only electric light (Philips Master TL-D Super 80, 36 W/380, Copenhagen, Denmark) turned on constantly. The samples that were stored in darkness were kept in the same room inside two black plastic bags. The samples were stored at room temperature during the entire storage period. During the storage experiment, the temperature readings were recorded by a portable thermometer (EL-EnviroPad-TC, Corintech, UK) via a thermocouple probe. A diagram of packaging and storage conditions is shown in Figure 8 . The minimum, average, and maximum of the storage temperatures were $20.3{ }^{\circ} \mathrm{C}, 22.2{ }^{\circ} \mathrm{C}$, and $24.2{ }^{\circ} \mathrm{C}$, respectively. The samples were analyzed after approximately $0,1,3,5$, and 7 months of storage (or exactly $0,32,101,168$, and 225 days, respectively). In the following, the time points will be given as the approximate number of months. The two replicates of each storage condition were analyzed on each day of analysis and, from each of these, two sub-replicates were prepared for all the analyses. Overall, this resulted in four replicates for each storage treatment on each day of analysis. In the sample preparation and the analysis steps, the handling of the samples was randomized. Four samples resulted in very atypical values and were excluded from the dataset.

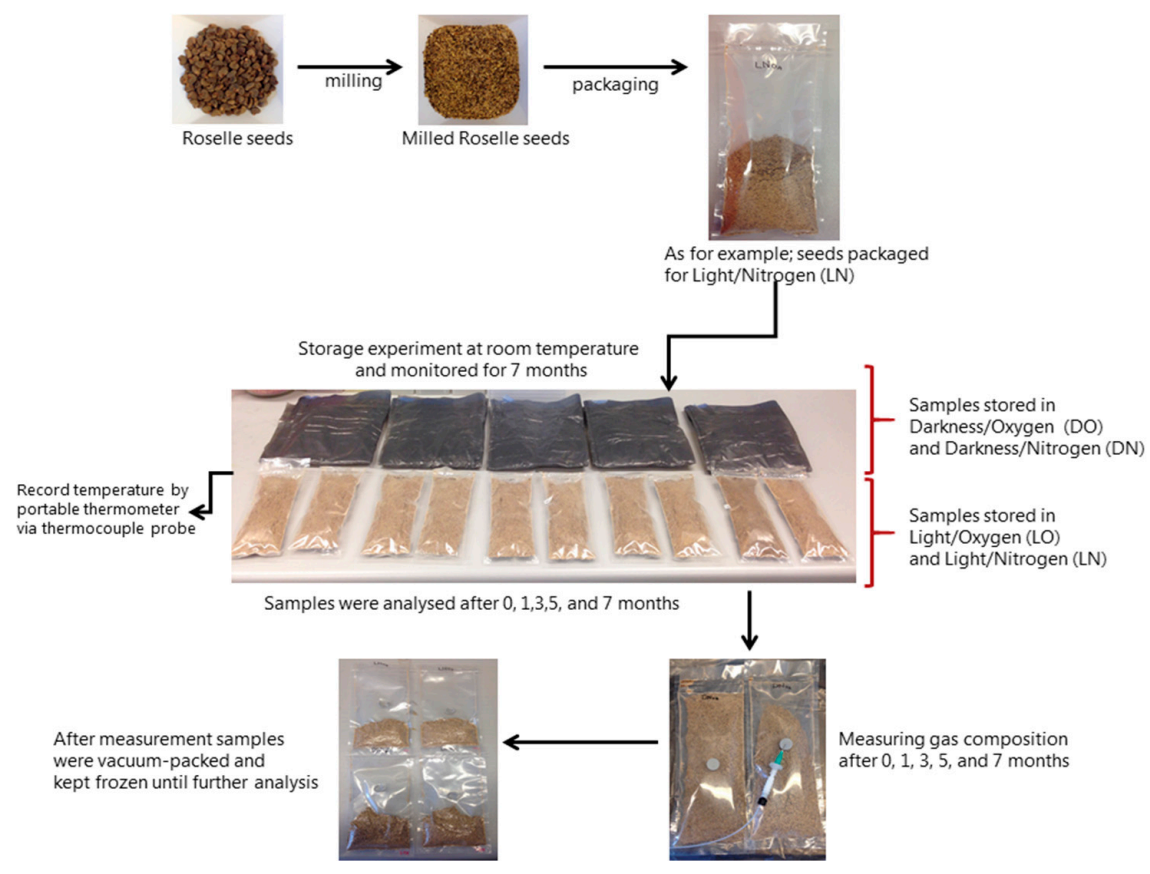

Figure 8. Diagram of packaging and storage conditions.

\subsection{Gas Composition}

Before the bags were opened for analysis, the gas composition was measured using a CheckMate 9900 (PBI Dansensor A/S, Ringsted, Denmark). After measurement, the sample was vacuum-packed and kept frozen until further analysis. The overall gas composition during the entire storage period is shown in Figure 1.

\subsection{Volatile Compound Analysis}

Dynamic headspace sampling (DHS) was applied to extract volatile compounds. The method was carried out as described by Juhari [19]. Twenty-five gram of milled seeds was put in a gas washing flask (500 mL) with a magnetic stirrer. The samples were equilibrated to $40^{\circ} \mathrm{C} \pm 1{ }^{\circ} \mathrm{C}$ in a circulating water bath and then purged with nitrogen $\left(100 \mathrm{~mL} \mathrm{~min}^{-1}\right)$ for $40 \mathrm{~min}$. Volatile compounds were collected on a Tenax-TA traps (Markes International, Llantrisant, UK). 
The trapped volatiles were thermally desorbed (TurboMatrix 350, Perkin Elmer, Shelton, CT, USA) and transferred to a gas chromatography-mass spectrometry (7890A GC-system interfaced with a 5975C VL MSD from Agilent Technologies, Palo Alto, CA, USA) including a DB-Wax column ( $30 \mathrm{~m} \times$ $0.25 \mathrm{~mm} \times 0.50 \mu \mathrm{m})$. Peak areas and mass spectra were extracted from the chromatograms using the PARAFAC2 based software PARADISe (University of Copenhagen, Copenhagen, Denmark) [26] and mass spectra were identified using the NIST05 database. Peak areas were used as relative measures of concentration. Volatile compound identification was confirmed by comparison with retention indices (RI) of authentic reference compounds or retention indices reported in the literature.

\subsection{Data Analysis}

One-way analysis of variance (ANOVA) was performed using the software JMP (version 13.0, SAS Institute Inc., Cary, NC, USA). Principal component analysis (PCA) with autoscaling was run using the Latentix software (LatentiX 2.0. Latent5, Copenhagen, Denmark).

\section{Conclusions}

To our knowledge, this is the first time that changes of volatile compounds during storage of milled Roselle seeds are reported.

The present study demonstrates that milled Roselle seeds are a potential ingredient for food purposes because they contain high levels of protein, lipid and total dietary fiber. Besides that, we have shown that milled Roselle seeds exhibit good water and oil absorption capacity, which can be beneficial if included in food products. Furthermore, this study points out the importance of controlling the storage conditions to conserve the quality of milled Roselle seeds. For optimal storage, milled Roselle seeds should be stored in darkness rather than light, and flushed with nitrogen because light and oxygen accelerate the oxidation processes in the packaged food. Storage under these conditions may provide a shelf life of three months without attaining off-flavor.

Acknowledgments: The work was financially supported by Ministry of Education, Malaysia and University Putra Malaysia through its Skim Latihan Akademik Bumiputera (SLAI) Scholarship Program. We thank Åse Hansen for her ideas and supports for this experiment, Kirsten Sjøstrøm and Lasse Dybmark for their skillful assistance in DHS/GC-MS analysis, AB Sharul AB Sahab for his technical assistance in operating the packaging machine, and Åsmund Rinnan for providing statistical software.

Author Contributions: M.A.P. analyzed chromatographic data, conducted some data analysis and supervised the research; N.H.J. performed the research, statistical analysis and wrote the paper. All authors read, edited, made corrections, and approved the final manuscript.

Conflicts of Interest: The authors declare no conflict of interest. The founding sponsors had no role in the design of the study; in the collection, analyses, or interpretation of data; in the writing of the manuscript, and in the decision to publish the results.

\section{References}

1. Grubben, G.; Denton, O. Resources of Tripical Africa 2. Vegetables; PROTA Foundation: Wageningen, The Netherlands; Backhuys Publishers: Leiden/Wageningen, The Netherlends, 2004.

2. Rao, P. Nutrient composition and biological evaluation of mesta (Hibiscus sabdariffa) seeds. Plant Foods Hum. Nutr. 1996, 49, 27-34. [PubMed]

3. Lim, T. Edible Medicinal and Non Medicinal Plants; Springer: Dordrecht, The Netherlends, 2012; Volume 3, ISBN 978-94-007-2533-1.

4. Wilson, F.D.; Menzel, M.Y. Kenaf (Hibiscus cannabinus), roselle (Hibiscus sabdariffa). Econ. Bot. 1964, 18, 80-91. [CrossRef]

5. Hainida, E.; Ismail, A.; Hashim, N.; Mohd-Esa, N.; Zakiah, A. Effects of defatted dried roselle (Hibiscus sabdariffa L.) seed powder on lipid profiles of hypercholesterolemia rats. J. Sci. Food Agric. 2008, 1050, 1043-1050. [CrossRef]

6. El-Adawy, T.A.; Khalil, A.H. Characteristics of roselle seeds as a new source of protein and lipid. J. Agric. Food Chem. 1994, 42, 1896-1900. [CrossRef] 
7. Tounkara, F.; Amza, T.; Lagnika, C.; Le, G.W.; Shi, Y.H. Extraction, characterization, nutritional and functional properties of roselle (Hibiscus sabdariffa Linn) seed proteins. Songklanakarin J. Sci. Technol. 2013, 35, 159-166.

8. Nyam, K.-L.; Leao, S.-Y.; Tan, C.-P.; Long, K. Functional properties of roselle (Hibiscus sabdariffa L.) seed and its application as bakery product. J. Food Sci. Technol. 2014, 15, 3830-3837. [CrossRef] [PubMed]

9. Gaya, I.; Mohammad, O.; Suleiman, A.; Maje, M.; Adekunle, A. Toxicological and lactogenic studies on the seeds of Hibiscus sabdariffa Linn (Malvaceae) extract on serum prolactin levels of albino wistar rats. Internet J. Endocrinol. 2009, 5, 1-6.

10. Mohamed, B.B.; Sulaiman, A.A.; Dahab, A.A. Roselle (Hibiscus sabdariffa L.) in Sudan, cultivation and their uses. Bull. Environ. Pharmacol. Life Sci. 2012, 1, 48-54.

11. Eltayeib, A.A.; Elaziz, A.A. Physicochemical properties of Roselle (Hibiscus sabdariffa L.) seeds oil ( Elrahad-1) in North Kordofan, Sudan. J. Sci. Innov. Res. 2014, 3, 578-582.

12. Dhar, P.; Kar, C.; Ojha, D.; Pandey, S.; Mitra, J. Chemistry, phytotechnology, pharmacology and nutraceutical functions of kenaf (Hibiscus cannabinus L.) and roselle (Hibiscus sabdariffa L.) seed oil: An overview. Ind. Crops Prod. 2015, 77, 323-332. [CrossRef]

13. Holse, M.; Skov, T.; Hansen, Å. Oxidative storage stability of roasted marama beans (Tylosema esculentum). Food Res. Int. 2012, 47, 385-391. [CrossRef]

14. Ismail, A.; Ikram, E.H.K.; Nazri, H.S.M. Roselle (Hibiscus sabdariffa L.) Seeds-nutritional composition, protein quality and health benefits. Food 2008, 2, 1-16.

15. FAO (Food and Agriculture Organization of the United Nations). Improving Nutrition through Home Gardening-A Training Package for Preparing Field Workers in Africa; Food and Nutrition Division in Collaboration with Plant Production and Protection Division, FAO: Rome, Italy, 2001. Available online: http:/ / www.fao.org/es/ESN/Educate.htm (accessed on 25 October 2017).

16. Bhat, R.; Yahya, N.B. Evaluating belinjau (Gnetum gnemon L.) seed flour quality as a base for development of novel food products and food formulations. Food Chem. 2014, 156, 42-49. [CrossRef] [PubMed]

17. Samy, M. Chemical and nutritional studies on roselle seeds (Hibiscus sabdariffa L.). Zeitschris fiir Erniihrungswissenschas 1980, 19, 47-49. [CrossRef]

18. Emmy Hainida, K.; Amin, I.; Normah, H.; Mohd-Esa, N. Nutritional and amino acid contents of differently treated Roselle (Hibiscus sabdariffa L.) seeds. Food Chem. 2008, 111, 906-911. [CrossRef]

19. Juhari, N.H.; Petersen, M.A. Aroma profile and proximate composition of Roselle seeds: Effects of different origins and different sample preparation methods. In Proceedings of the 15th Weurman Flavour Research Symposium, Graz, Austria, 18-22 September 2017.

20. Jensen, P.N.; Sørensen, G.; Engelsen, S.B.; Bertelsen, G. Evaluation of quality changes in walnut kernels (Juglans regia L.) by Vis/NIR spectroscopy. J. Agric. Food Chem. 2001, 49, 5790-5796. [CrossRef] [PubMed]

21. Mexis, S.F.; Kontominas, M.G. Effect of oxygen absorber, nitrogen flushing, packaging material oxygen transmission rate and storage conditions on quality retention of raw whole unpeeled almond kernels (Prunus dulcis). LWT Food Sci. Technol. 2010, 43, 1-11. [CrossRef]

22. Wietstock, P.C.; Kunz, T.; Methner, F.J. Relevance of oxygen for the formation of Strecker aldehydes during beer production and storage. J. Agric. Food Chem. 2016, 64, 8035-8044. [CrossRef] [PubMed]

23. Zhang, N.; Chen, H.; Sun, B.; Mao, X.; Zhang, Y.; Zhou, Y. Comparative analysis of volatile composition in Chinese truffles via GCxGC/HR-TOF/MS and electronic nose. Int. J. Mol. Sci. 2016, 17, 412. [CrossRef] [PubMed]

24. AOAC. AOAC Official Methods of Analysis, 20th ed.; AOAC International: Gaithersburg, MD, USA, 2016.

25. Megazyme, I.I.L. Total Dietary Fibre Assay Procedure; Megazyme International Ireland Limited: Wicklow, Ireland, 2005; pp. 1-19.

26. Johnsen, L.G.; Skou, P.B.; Khakimov, B.; Bro, R. Gas chromatography-mass spectrometry data processing made easy. J. Chromatogr. A 2017, 1503, 57-64. [CrossRef] [PubMed]

Sample Availability: Samples are not available from authors.

(C) 2018 by the authors. Licensee MDPI, Basel, Switzerland. This article is an open access article distributed under the terms and conditions of the Creative Commons Attribution (CC BY) license (http://creativecommons.org/licenses/by/4.0/). 